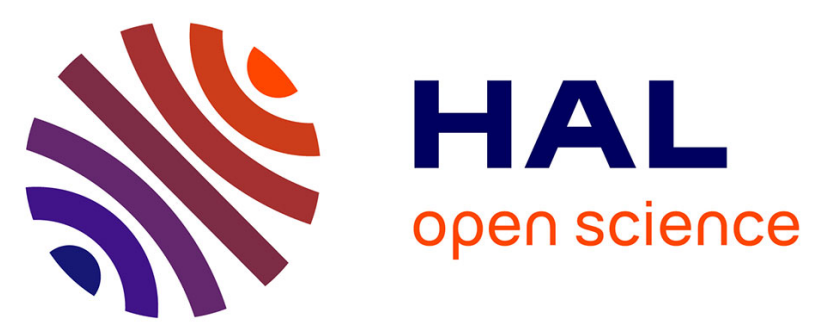

\title{
Methods to Determine Interaction Interfaces Between $\beta$-Arrestins and Their Protein Partners
}

Thomas Bourquard, Astrid Musnier, Aurélie Trefier, Flavie Landomiel, Thomas Boulo, Eric Reiter, Pascale Crépieux, Anne Poupon

\section{- To cite this version:}

Thomas Bourquard, Astrid Musnier, Aurélie Trefier, Flavie Landomiel, Thomas Boulo, et al.. Methods to Determine Interaction Interfaces Between $\beta$-Arrestins and Their Protein Partners. Beta-arrestinsmethods and protocols, 1957, , pp.177-194, 2019, Methods in Molecular Biology, 10.1007/978-1-49399158-7_12 . hal-02373790

\section{HAL Id: hal-02373790 \\ https://hal.science/hal-02373790}

Submitted on 21 Nov 2019

HAL is a multi-disciplinary open access archive for the deposit and dissemination of scientific research documents, whether they are published or not. The documents may come from teaching and research institutions in France or abroad, or from public or private research centers.
L'archive ouverte pluridisciplinaire HAL, est destinée au dépôt et à la diffusion de documents scientifiques de niveau recherche, publiés ou non, émanant des établissements d'enseignement et de recherche français ou étrangers, des laboratoires publics ou privés. 


\section{Methods to determine interaction interfaces between $\beta$-arrestins and their protein partners.}

Bourquard T.1,2, Musnier A. ${ }^{1}$, Tréfier A. ${ }^{1}$, Landomiel F. ${ }^{1}$, Boulo T. ${ }^{1}$, Reiter E., Crépieux P. ${ }^{1}$, Poupon A. ${ }^{1 *}$

1: PRC, INRA, CNRS, Université François Rabelais-Tours, 37380, Nouzilly, France.

2: Department of Human and Molecular Genetics, Baylor College of Medicine, Houston, Texas 77030, USA

* : corresponding author, Anne.poupon@inra.fr

\section{Abstract}

$\beta$-arrestins are so-called hub proteins: they make complexes with many different partners, assembling functional complexes, and thereby fulfilling their biological function. The importance of this process in G protein-coupled receptor (GPCR) signalling has been fully demonstrated for many different receptors. For direct interactions, determining the interface regions, on $\beta$-arrestins and on the partners, is crucial for understanding the function of the complex. Indeed, this brings information on which proteins can interact simultaneously with $\beta$-arrestins, or on the contrary, which partners are exclusive. We present here a method in two steps: protein-protein docking allows finding a limited number of peptides predicted to be involved in the interaction; and then experimental that might be used for validating the prediction.

\section{Keywords}

Protein complex

$\beta$-arrestin partners

Interface region

Protein-protein docking

\section{Running title}

Interfaces between $\beta$-arrestins and their partners 



\section{Introduction}

$\beta$-arrestins play key roles in G protein-coupled receptor (GPCR) signalling through their interactions with hundreds of proteins (1). Characterizing the interaction regions between $\beta$-arrestins and their partners is an important step in the understanding of the functional roles of these interactions. In particular, it allows determining the partners that are in competition with each other (XOR), and those whose interactions are compatible (AND), and can thus bind simultaneously on a single $\beta$-arrestin molecule (2). This knowledge can lead to the understanding of how different signalling pathways can be triggered simultaneously, or on the contrary compete each other $(3,4)$, or how mutations in one partner can affect to various extents its different partners $(5,6)$.

The gold standard in interface determination is the determination of complex 3D structures, either by crystallography, or using NMR. However, this represents a lot of work and requires the production of both proteins at high yield. Moreover, in the case of signalling proteins, such as $\beta$-arrestins and their partners, the affinities are generally low, and stabilizing the complex can be tricky. Aside from the 3D structure, a widely used experimental method is to evaluate the binding between one partner and mutants of the other one, either in terms of affinity, or in terms or relative binding as compared to the wild type. However, single mutations, especially alanine mutations, can lead to undetectable modulation of the affinity, although they affect amino acids involved in the interaction. Moreover, the throughput of such a method is very low. A higher throughput can be achieved using peptide-array based methods (7-9), in which overlapping peptides of one partner are arrayed on solid support and exposed to the second partner. This can be followed by alanine-scanning of positive peptides to refine the interaction map. Recently, mass spectrometry-based approaches have been developed $(\mathbf{1 0}, 11)$. The principle is to submit the complex either to hydrogen/deuterium exchange, or to enzymatic digestion, and to identify through mass spectrometry peptides that are protected by the interaction. However, these methods are time-consuming and require specialized equipment and skills.

We have recently developed a method for determining the interaction regions in protein complexes, which allows us to predict and validate the geometry of the assembly of $\beta$ arrestin with the receptor, c-Src and the ERK signalling module (Raf, MEK and ERK)(12). In addition, results obtained from such an approach allows us to make hypotheses, which can be experimentally validated, for instance on the mechanism of 
phosphorylation of residue T383 in $\beta$-arrestin upon activation of the receptor(13). This method consists of two main steps. First, a computational method, based on an in-house protein-protein docking algorithm (14-16), allows determining four regions of the sequences of each partner possibly involved in the interaction. Second, these regions are used to design peptides that are used for refinement and experimental validation of the prediction.

This experimental validation can be conducted using various protocols. Although positive results using only one method are enough for the validation, interactions between a protein and a peptide are not easily detected. We give here three different possible validation methods, ranked in order of difficulty, but also of sensitivity. The first method we describe here is GST-pulldown approach, which is used to visualize competition between the partner and a peptide, for binding to $\beta$-arrestin (figure 1A). If positive, the results of GST-pulldown validate the prediction of the interface.

However, GST-pulldown is not a very quantitative method and requires large quantities of both purified proteins. As an alternative, we suggest using Homogenous Time Resolved Fluorescence (HTRF) to assess the competition (figure 2A). HTRF combines fluorescence resonance energy transfer technology (FRET) with time-resolved measurement (TR). In TR-FRET assays, a signal is generated through FRET between a donor (long-lived fluorescence) and an acceptor (short-lived fluorescence) molecule when in close proximity to each other (i.e. the distance between the two fluorophores is less than $1.8 \mathrm{x}$ the radius of Förster, i.e. $<10 \AA$ or $1 \mathrm{~nm})$. Time delay $(50-150$ microseconds) between the initial light excitation and fluorescence measurement minimizes the contribution of all non-specific short-lived fluorescence emissions. Buffer and media interference is dramatically reduced by dual-wavelength detection, and the final signal is proportional to the extent of product formation. Specific fluorophores are used in HTRF forming different TR-FRET systems like Europium cryptate donor (Eu3+) or Terbium donor (Tb2+). These ions are not fluorescent on their own, since they need a light-collection device to be excited. HTRF technology has been applied to many antibody-based assays including GPCR signaling (cAMP and IP1), kinases, cytokines and biomarkers, bioprocess (antibody and protein production), as well as assays for proteinprotein, protein-peptide, and protein-DNA/RNA interactions. Here, we describe how to measure FRET differences between two purified tagged-proteins in the presence of competing peptides designed to interact with either $\beta$-arrestin or its protein partner. 
If the affinity between $\beta$-arrestin and its partner is high, the affinity of the peptide might not be sufficient for competition. In that case, we have shown that biolayer interferometry can be used to evaluate the specificity of the peptide (figure 3A). Biolayer interferometry is very similar in its principles to surface plasmon resonance (SPR), but has the great advantage of being a non-fluidic system, which is easier to handle and maintain. It relies on the detection of the association of molecules on a surface at the tip of a biosensor, constituted mainly of an optic fiber (1). This biosensor is first dipped in a well containing the first partner, which associates to the surface, and this association can be observed through the analysis of light reflected at the tip of the biosensor (2). The biosensor can then be dipped in a second well containing the second partner, and the association with the first partner can be measured using the same principle (3). Finally, the biosensor can be dipped in a well containing only buffer, which allows monitoring the dissociation of the two partners. In our case, the first partner is the peptide designed to interfere with the association of $\beta$-arrestin with its partner, and biolayer interferometry is used to measure the association of $\beta$-arrestin with this peptide. We use biotinylated peptides, which can be loaded on streptavidin biosensors. The advantage is that the interaction affinity between biotin and streptavidin is very high, guaranteeing that the dissociation observed at step 3 is that of the two loaded components, and not the dissociation of the first component from the biosensor. 


\section{Materials}

Unless otherwise mentioned, all chemicals are from Sigma Aldrich.

\subsection{GST glutathione S-transferase (GST)-pulldown}

1. Plasmids and bacteria: GST-Raf1-RBD expressed from pGEX-2T was generously provided by Dr. Véronique Fafeur (Pasteur Institute, Lille). The Raf1-RBD (Rasbinding Domain) corresponds to amino acids 51 to 131 of Raf1 and is the minimum domain required for binding to Ras-GTP. The pGEX-2T plasmid (GE Healthcare, Buckinghamshire, UK) was used as a negative control. C(6His)-tagged human $\beta$-arrestin 1 was from Gentaur (San Jose, CA, USA). Chemo-competent NEB-5 $\alpha$ bacteria were from New England Biolabs, Ipswish, MA, USA). Agar (LBAgar Lennox) plates and L-broth (LB-medium Lennox powder), both purchased at MP Biomedicals, Illkirch, France, contained $100 \mu \mathrm{l} / \mathrm{ml}$ ampicillin (stocksolution $100 \mathrm{mg} / \mathrm{ml}$ ).

2. Lysis buffer used for protein production in E. coli: $250 \mathrm{mM} \mathrm{NaCl}, 10 \mathrm{mM} \mathrm{MgCl}, 10$ mM EDTA, $1 \%$ Triton, $250 \mu \mathrm{g} / \mathrm{ml}$ lysozyme, $10 \mathrm{mM}$ DTT, $1 \mathrm{mM}$ PMSF, $3.4 \mathrm{U}$ DNAse I, $1 \mathrm{X}$ protease and phosphatase inhibitor cocktail II (Thermo Fisher Scientific Inc. Waltham, MA, USA), in phosphate-buffered saline (PBS). This buffer has to be prepared extemporaneously and kept on ice until use.

3. Buffers used for GST (glutathione S-transferase) pull-down. a) fusion protein binding buffer: 10 mM Tris- $\mathrm{HCl}$ pH 8.0, $100 \mathrm{mM} \mathrm{NaCl}, 0.5$ \% NP40, 20 mM EDTA, $1 \mathrm{mM}$ PMSF or $1 \mathrm{X}$ protease and phosphatase inhibitor cocktail II. b) HNTG protein-protein interaction buffer: $20 \mathrm{mM}$ Hepes, pH 7.9, $50 \mathrm{mM} \mathrm{KCl}, 2.5 \mathrm{mM}$ $\mathrm{MgCl}_{2}, 1 \mathrm{mM}$ DTT, $10 \%$ glycerol, $1 \mathrm{X}$ protease and phosphatase inhibitor cocktail II. If prepared in advance, omit the protease/ phosphatase inhibitors in the stock solutions.

4. Laëmmli buffer $2 \mathrm{X}$ was prepared with $8 \%$ SDS, $5 \% \beta$-mercapto-ethanol, $10 \%$ glycerol (w/v), $32 \mathrm{mM}$ Tris-HCl pH 6.8, $0.01 \%$ bromophenol blue, and stored at room temperature. Western blot blocking solution was made with PBS/0.1 Tween 20 with $5 \%$ bovine serum albumin.

5. Polyclonal anti- $\beta$-arrestin primary antibody, diluted 1: 2,000, was from Abcam, Cambridge, England. IRDye Alexa fluor 680-labelled secondary antibody, diluted 
1: 15,000, was from Licor, Lincoln, NE, USA. Anti-GST antibody, diluted 1: 500, was from Life technologies, Carlsbad, CA, USA.

6. Competing peptides, synthesized by Genecust Laboratories (Dudelange, Luxembourg), were designed following prediction of the docking interface, as described above in section 3.1.

\subsection{Homogeneous Time Resolved Fluorescence (HTRF)}

Prepare all solutions (purified myc- $\beta$-arrestin1 (0.180 $\mu \mathrm{g} / \mu \mathrm{l}$, Origene \#TP321737) and ERK peptides $(100 \mu \mathrm{g} / \mu \mathrm{l})$ ) in PBS (1X)-Tween $200.1 \%$ at $4^{\circ} \mathrm{C}$ and store purified proteins at $-80^{\circ} \mathrm{C}$, acceptor- and donor-fused antibodies and peptides at $-20^{\circ} \mathrm{C}$. Prepare all reagents in 384-well plate for a final volume of $20 \mu \mathrm{l}$ which contains $10 \mu \mathrm{l}$ of $2 \mathrm{X}$ purified protein $\left([\text { myc- } \beta \text {-arrestin } 1]_{\text {initial }}=0.4 \mathrm{ng} / \mu \mathrm{l}\right), 5 \mu \mathrm{l}$ of $4 \mathrm{X}$ peptide ([ERK peptide $\left.]_{\text {initial }}=50 \mathrm{mM}\right)$ and $5 \mu \mathrm{l}$ of $4 \mathrm{X}$ HTRF donor-coupled antibody $([\alpha-\mathrm{c}-\mathrm{myc} \mathrm{Tb}$

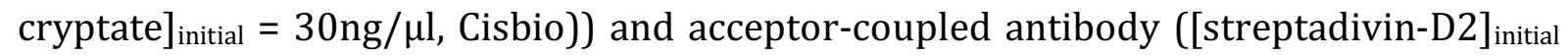
$=1000 \mathrm{ng} / \mu \mathrm{l}]$, Cisbio).

1. Prepare $10 \mathrm{ml}$ of PBS (1X)-Tween $200.1 \%$ : add $1 \mathrm{ml}$ of PBS $10 \mathrm{X}$ to $8.9 \mathrm{ml}$ of water, then add $100 \mu \mathrm{l}$ of Tween 20 . Mix gently to homogenate solution and store at $4^{\circ} \mathrm{C}$;

2. Gently thaw purified proteins on ice;

3. Dilute lyophilized peptide in DMSO, work on ice and store at $-20^{\circ} \mathrm{C}$;

4. Use white flat low volume 384-well plate to work with $20 \mu \mathrm{l}$ final volume.

5. Settings measurements are defined by using Mikrowin 2010 software and relative energy transfer rate of each condition is measured on microplate reader MITHRAS $^{2}$ LB 943 (Berthold technologies GmbH and Co.Kg, Germany).

\subsection{Interferometry}

1. 96-well black plates, without lid (ref \# 1608130, Greiner Bio-One, Kremsmünster, Austria)

2. Kinetic Buffer 10X (ref \#18-1092, 50 ml, Pall forte Bio, Fremont, CA, USA)

3. SA (streptavidin) biosensors (Pall forte Bio, Fremont, CA, USA)

4. Octet RED96 System (Pall forte Bio, Fremont, CA, USA)

5. Octet Software 9.0 version (Pall forte Bio, Fremont, CA, USA)

6. Biotinylated peptide $\alpha$ (=ligand, relevant peptide), stock suspension at $50 \mathrm{mM}$ in dimethylsulfoxide (DMSO)

7. Protein $\beta$ (= analyte, $\beta$-arrestin in our example), stock suspension at $1 \mu \mathrm{g} / \mu \mathrm{l}$ 
8. Biotinylated peptide $\gamma$ (non-relevant ligand), stock suspension at $50 \mathrm{mM}$ in DMSO 


\section{Methods}

\subsection{Predicting the possible interaction regions and designing validation peptides}

1. Get the structure files corresponding to the two interacting partners, for example from RCSB (http://www.rcsb.org) (see Notes 1 and 2).

2. If the files contain more than one chain, for example if the atomic coordinates correspond to a homo-multimer, or if the structures have been determined in complex with another partner, remove irrelevant chains from file. Heteroatoms should also be removed. If the partner is constituted of more than one chain (for example an antibody, comprising heavy and light chains), it should be renumbered as a single chain (see Note 3 ).

3. Choose the partner that will not move (usually designated as the "receptor") and the partner that will move around the receptor partner (designated as the "ligand"). This choice does not change the prediction. However, all the proposed docking poses will be superimposed on the receptor partner. Consequently, if you are more interested on the interface on one of the partners, choose it as receptor. If you are interested in both interfaces, choose the smallest partner as ligand, the computations will be a bit faster.

4. Run PRIOR (see Note 4).

5. PRIOR outputs a file named "peptides.txt", which is a list of peptides. From our benchmarks, one of the first four peptides does belong to the interface, and the three others are often part of the interface also. Thus, it is recommended to consider using the four top-ranked peptides.

6. Each peptide computed by PRIOR is 15 residues long. Each peptide should be used for validation, but also a peptide starting and ending three residues upstream and a peptide starting and ending three residues downstream. Indeed, we have often observed that the computed peptide might not be soluble, but the upstream and/or downstream peptides are. Thus, designing three peptides for each predicted interacting residues stretch increases the chance to have at least one peptide suitable for experimental validation (see Note 5).

\subsection{GST-pulldown}

1. Producing GST-Raf1-RBD fusion protein in E. coli. 
a. On day 1, transform competent NEB-5 $\alpha$ bacteria with either a pGEX-2T plasmid encoding GST- Raf1-RBD or an empty plasmid encoding GST alone, which is used as a control. Spread bacteria on agar plates containing 100 $\mu \mathrm{g} / \mathrm{ml}$ ampicillin and incubate overnight $(\mathrm{ON})$ at $37^{\circ} \mathrm{C}$.

b. On day 2, amplify bacteria by picking one colony into $25 \mathrm{ml} \mathrm{L-broth}$ containing $100 \mu \mathrm{g} / \mathrm{ml}$ Ampicillin. Incubate $\mathrm{ON}$ at $37^{\circ} \mathrm{C}$ in a shaking incubator at $200 \mathrm{rpm}$.

c. On day 3, dilute the $25 \mathrm{ml}$ of culture into $225 \mathrm{ml} \mathrm{LB} / \mathrm{Amp}$, and grow $3 \mathrm{~h}$ at $37^{\circ} \mathrm{C}$ at $200 \mathrm{rpm}$. Ten (10) $\mathrm{ml}$ of the $250 \mathrm{ml}$ culture are stored at $4^{\circ} \mathrm{C}$ until step 1.d as a control of the non-induced condition. In the remaining $240 \mathrm{ml}$, induce protein expression by adding $2.4 \mathrm{ml}$ EtOH $(1 \%$ final concentration $)+600 \mu \mathrm{l}$ IPTG $(250 \mu \mathrm{M}$ final concentration $)$ and grow bacteria for $3 \mathrm{~h}$ at $37^{\circ} \mathrm{C}$ in a shaking incubator at $200 \mathrm{rpm}$.

d. Proceed with induced and non-induced bacteria lysis on ice. Centrifuge bacteria culture at 2,500 $\mathrm{g}$ for $30 \mathrm{~min}$ at $4^{\circ} \mathrm{C}$, in Nalgene bottles. Recover the pellet and centrifuge the supernatant again for $20 \mathrm{~min}$. Both pellets should be recovered and pooled in lysis buffer $(500 \mu \mathrm{l}$ for $10 \mathrm{ml}$ of culture), in a $15-\mathrm{ml}$ Falcon tube. Incubate $\mathrm{ON}$ at $4{ }^{\circ} \mathrm{C}$ on a rotating wheel. The next day, the lysates are sonicated three times for $30 \mathrm{sec}$ on ice, centrifuged for one hour at $12,000 \mathrm{~g}$ and filtered on $0.22 \mu \mathrm{m}$ filters. Aliquots of non-purified GST-fusion protein controls $(60 \mu \mathrm{l}$ for the induced condition and $12.5 \mu \mathrm{l}$ for the non-induced condition) are diluted in equal volumes of $2 \mathrm{X}$ Laëmmli buffer $(\mathrm{v} / \mathrm{v})$ and stored at $-20^{\circ} \mathrm{C}$ until use (see Note 6).

\section{In vitro protein-protein interaction.}

a. Preparation of Glutathione-Sepharose 4B beads. Pipette $20 \mu \mathrm{l}$ of slurry beads $(50 \%$ in EtOH) per $\mathrm{ml}$ of initial bacteria culture. Centrifuge the beads at $500 \mathrm{~g}$ for $5 \mathrm{~min}$, resuspend them in $10 \mathrm{ml}$ PBS, and incubate at $4^{\circ} \mathrm{C}$ on a rotating wheel for 1.5 hour. Centrifuge the beads again at 500 $g$ for 5 min and re-suspend in an equal volume of PBS.

b. Purification of the fusion protein. Incubate the whole bacteria lysate with $4.8 \mathrm{ml}$ of slurry beads prepared in 3.2.2.a, and with $200 \mu \mathrm{l}$ for the 
non-induced condition at $4^{\circ} \mathrm{C}$ on a rotating wheel for $30 \mathrm{~min}$. Centrifuge at $500 \mathrm{~g}$ for $5 \mathrm{~min}$, then wash the beads twice with PILB. Beads are next saturated with $5 \mathrm{ml}$ of $10 \% \mathrm{BSA}$ under rotation at $4^{\circ} \mathrm{C}$ for $10 \mathrm{~min}$, washed once in $1 \mathrm{ml}$ PILB, and centrifuged at $500 \mathrm{~g}$ for 5 min before removing the supernatant. Beads can be used immediately, once extensively dried for $30 \mathrm{~min}$ at $37^{\circ} \mathrm{C}$. Alternatively, they can be stored as $50 \mu \mathrm{l}$ dried aliquots at $-20^{\circ} \mathrm{C}$ for future use, after first resuspending them in PILB and centrifuging them again at $500 \mathrm{~g}$ for 5 $\min$.

c. The reaction mix comprises 25 ng of recombinant human His-tagged $\beta$ arrestin 1, $50 \mu \mathrm{l}$ of dried beads coated with either GST-Raf1-RBD or GST, and $0.5 \mathrm{mM}$ (see Note 7) of one of the competing peptides or control peptide (Figure 1A). These quantities correspond to a $\beta$ arrestin/ peptide molar ratio of 10 to 1 . The volume is completed to 1 $\mathrm{ml}$ with HNTG buffer, and the reaction mix is placed at $4{ }^{\circ} \mathrm{C}$ on a rotating wheel for 1 hour (see Note 8). The beads are then washed 6 times with $1 \mathrm{ml} \mathrm{HNTG} \mathrm{(each} \mathrm{time,} \mathrm{centrifuge} \mathrm{at} 500 \mathrm{~g}$ for $5 \mathrm{~min}$ ).

d. Competing peptides cover amino acids 30-38 of human $\beta$-arrestin 1 (HIDLVEPVD) or aminoacids 65-74 (KQRTVVNVRN) on Raf1. The control peptide corresponds to amino acids 69-77 (DVLGLSFRK) of $\beta$ arrestin 1 , a region that is outside of the predicted Raf $1 / \beta$-arrestin 1 interface.

3. After the last centrifugation, dried beads are re-suspended in $2 \mathrm{X}$ Laëmmli buffer $(\mathrm{v} / \mathrm{v})$, boiled at $100^{\circ} \mathrm{C}$ for $30 \mathrm{~min}$, and centrifuged for $10 \mathrm{~min}$ at 12,000 $g$. Recover the supernatants (avoid pipetting beads) and load them onto $10 \%$ SDS-PAGE gels. After the transfer of the resolved proteins onto nitrocellulose membrane, dip the latter in $10 \mathrm{ml}$ of blocking solution for one hour at RT, then incubate the membrane ON with a polyclonal anti- $\beta$-arrestin primary antibody and then with IRDye Alexa fluor 680-labelled secondary antibody, all diluted in blocking buffer. Protein loading homogeneity is monitored by stripping, washing and reprobing membranes with a polyclonal anti-GST antibody against GST-raf1-RBD. 


\subsection{HTRF}

Carry out all procedures on ice to preserve protein and peptide stability.

1. Peptide-based validation of the protein partner interaction area. Several peptides are designed at the interface region of each partner. The protocol given here allows testing the specific interaction of the peptides belonging to the interface region of one partner with the second partner. This protocol is illustrated here for the interaction of ERK peptides with $\beta$-arrestin 1 (Figures 2A-C).

e. Dilute $\beta$-arrestin 1 to $2 \mathrm{ng} / \mu \mathrm{l}$ in PBS(1X)- $0.1 \%$ tween 20 and dispense $5 \mu \mathrm{l}$ per well in a low bottom 384 well plate.

f. Dilute the ERK peptides to $2 \mathrm{mM}$ in PBS(1X)-0.1\% Tween 20 and dispense $10 \mu \mathrm{l}$ per well.

g. Cover the plate with adhesive and aluminum foils and incubate overnight at $4^{\circ} \mathrm{C}$ under smooth agitation.

h. Mix $3 \mathrm{ng}$ of the donor-coupled antibody (or protein) and $50 \mathrm{ng}$ of the acceptor-coupled antibody (or protein) in $5 \mu$ and dispense in the well.

i. Incubate $1 \mathrm{~h}$ at room temperature and keep the plate several days at $4^{\circ} \mathrm{C}$ (see Notes 10-13).

2. Open microplate reader MITHRAS ${ }^{2}$ LB 943 (Berthold technologies $\mathrm{GmbH}$ and Co.Kg, Germany) and Mikrowin 2010 software.

3. The reader performs two sequential readings at $620 \mathrm{~nm}$ (donor) and $665 \mathrm{~nm}$ (acceptor) emission wavelengths. In mean windows of Mikrowin 2010 software, click on "Instrument" in menubar, then in "Excitation filter slide", introduce bar with excitation filter 620nm. Then click in "Emission filter slide" and introduce bar with emission filter $665 \mathrm{~nm}$.

4. Load a predefined protocol HTRF by clicking on "Open Template" tab in mean window. Select TR-fluorescence, then HTRF Tb_red_348.par file.

5. Define measurements sequence parameters in "Option" tab.

6. A dialog box opens with two tabs : Samples and Measurement, First click on "Samples", enter parameters of plate format:

- in plate type : Berthold 384-No33505,

- in plate mode : Measurement 
- in Measure order : By Rows and click on Meander.

Then select wells for measurements

Second to features of the measurement operation, click on "Measurement". Three columns appear. Left column describe the settings of the chosen operation. Check that pre-select steps of measurement are selected : "Delay", "Skake”, “Lumi.Label”, "Lumi.kinetic”, "Fluor.kinetic” and "Fluor.kinetic".

In middle column, double click in "HTRF-Tb-red" to verify parameters:

- Counter time : $1.00 \mathrm{sec}$

- Counter : photon

- Use : filter

- $\quad$ Reading position : top

- $\quad$ Aperture TRF filter : 384

- Excitation filter : 340x26 HTRF Tb cryptate

- Excitation optic : default

- Emission filter : 620xm10 Eu cryptate

- Cycle Time : $2000 \mu \mathrm{s}$

- Delay Time : $50 \mu \mathrm{s}$

- $\quad$ Reading Time : $400 \mu \mathrm{s}$

- Click second measurements

- Excitation filter : 340x26 HTRF Tb cryptate

- Emission filter : 665xm7uv XL665, APC

- Operation mode : By plate

7. Before to start reading, give name of your experiment in "Plate ID" in the toolbar

8. Click "START", introduce your place in the reader.

9. The live data measurement can be displayed by clicking on "measurement"

10. Calculate energy transfer rate (see Note 13)

\subsection{Interferometry}

1. Dilute the biotinylated peptides $\alpha$ and $\gamma$ (called "ligands"), in $1 X$ kinetic buffer to the determined concentrations (see Notes 14 and 15). $200 \mu \mathrm{l}$ per well are needed. 
2. Dilute the protein $\beta$ (called "analyte") in kinetic buffer. Five association curves (i.e. 5 concentrations of the analyte) are necessary to measure a reliable $\mathrm{Kd}$ (see Note 16). One well must be left empty, i.e. with no analyte, only kinetic buffer.

3. Load the $200 \mu \mathrm{l}$ of protein solutions or kinetic buffer in a black plate according to Figure 3B

4. Soak 2 columns of biosensors in $200 \mu \mathrm{l}$ of kinetic buffer in a black plate positioned under the sensor tray.

5. Open the Octet Data Acquisition 9.0 software, open a new experiment wizard and enter your plate scheme in "plate definition".

6. In "assay definition", set the experiment up as follows (Figure 3B):

j. $\quad$ set a $60 \mathrm{sec}$ baseline in column 1

k. set a $600 \mathrm{sec}$ loading step in column 2

l. set a $60 \mathrm{sec}$ baseline in column 1

m. set a 60 sec baseline in column 3

n. set a $600 \mathrm{sec}$ association in column 4

o. set a $600 \mathrm{sec}$ dissociation in column 3

p. click on "new assay". The following steps will appear in a different color

q. set a 60 sec baseline in column 5

r. set a $600 \mathrm{sec}$ loading step in column 6

s. set a 60 sec baseline in column 5

t. $\quad$ set a $60 \mathrm{sec}$ baseline in column 7

u. set a $600 \mathrm{sec}$ association in column 4

v. set a $600 \mathrm{sec}$ dissociation in column 7

All the steps are performed at $30^{\circ} \mathrm{C}$ and under $1000 \mathrm{rpm}$ shaking.

7. In "sensor assignment", locate the 2 biosensors columns, containing peptides $\alpha$ and $\gamma$, as they appear in the sensor tray. The 2 columns should appear in 2 different colors, the same colors as the steps before. By right-clicking on the 
second biosensor column (the one loaded in the non-relevant peptide $\psi$ ), select "reference".

8. Start reading.

9. Open the Data Analysis 9.0 software and load your experiment in "data selection":

10. Each curve must be corrected twice: first by subtracting the curve obtained from the wells without protein $\beta$ (line A according to figure $3 \mathrm{~B}$ ), and second by subtracting for each curve obtained on the relevant peptide $(\alpha)$ its counterpart on the non-relevant peptide $(\gamma)$. To do so, in "processing", go to the step 1 part and click on "sensor selection". In the "sensor tray", the biosensors should appear as sample sensors in the column 1 and reference sensors in column 2 . If not, change their settings by right clicking on them. In the "sample plate map", right-click on the "no analyte" well and set it as a reference sensor as well. Be sure that the selection boxes next to the reference sensor column and the non-analyte well, are selected.

11. In "processing", go to step 2. Select "subtraction" and "double reference". The subtraction calculation formula should appear in the box.

12. In "processing", go to step 3. Select "Align Y axis" on "association".

13. Click on "Process data".

14. In "processed data", select the fitting model corresponding to your protein sample (typically the 1:1 model). The analysis must be performed for all the curves at once. To do so, select "global analysis" and "by color" (it implies that all the curves should appear in the same color; to do so, select them all, rightclick and select a random color). The Kd and other parameters are shown in the table (see Notes 17-19, figure 3C). 


\section{Notes}

1. The list of PDB files corresponding to a given protein appears on the Uniprot page of the protein, in the "Structure section". If there is more than one choice, the structure corresponding to the largest region should be chosen. In case there are multiple files corresponding to this criterion, the one with the lowest resolution should be preferred. Finally, read carefully the corresponding Protein Data Bank (http://www.rcsb.org (17) page, in order to see if the structure contains ligands, inhibitors, glycosylations, etc.

2. If the 3D structure of one of the partners has not been determined, it is possible to use the structure of a very close homologue. This is the case for $\beta$-arrestins 1 and 2: the 3D structure of the human proteins has not been determined, but only those of the bovine homologues. However, the only sequence differences between human and bovine proteins lie in the C-terminal tails, which are not present in the 3D structures. Consequently, the bovine structures can be used.

3. To remove chains and hetero-atoms, PyMol software (https://www.pymol.org/) can be used.

4. At this step, PRIOR can be replaced by another protein-protein docking method, but there will be no automated peptide design. In that case this can be done manually: from the predicted complex 3D structure, list the amino acids in each partner that are involved in the interaction. For each stretch of residues predicted to be at the interface, design a 15-aa long peptide by extending this stretch in both directions (towards the $\mathrm{N}$ - and C-term). This procedure can also be applied for an "educated-guess" of the interface regions.

5. Regarding the design of peptides, the rules given in "Methods" should be applied with discernment, and some exceptions should be raised (Figure 4):

a. If the computed peptide starts at position 1 of the sequence, no upstream peptide should be used. Conversely, if the computed peptide ends at the last residue of the partner, no downstream peptide should be used. 
b. It sometimes happens that the computed peptide corresponds, in the $3 \mathrm{D}$ structure, to a sequence stretch whose central part is buried, which means that the two extremities are predicted to belong to the interface region. In that case, either the peptide should be ignored, or two different peptides should be generated by extending upstream and downstream, in order to define 15 residue-long peptides whose central regions are exposed and correspond to the extremities of the original peptide.

c. If the peptide corresponds to a helical region, it should be ignored. The reason is that a 15 residue-long peptide will only exceptionally fold as a helix.

d. Although there is no absolute rule to predict the solubility of a peptide, you should avoid sequences starting or ending with hydrophobic amino acids. If the computed peptide, or the upstream/downstream peptide, start or end with hydrophobic amino acids, try shifting upstream or downstream. Alternatively, the peptides can be shortened. The affinity having a tendency to decrease with the length of the peptide, the short peptides tend to be less favourable than longer ones. However, here also there is no prediction rule, and sometimes very nice results can be obtained with 8 residue-long peptides.

6. Each step of the fusion protein production and binding to the Glutathione beads can be monitored by SDS PAGE $10 \%$ and Coomassie blue staining, by comparing induced and non-induced conditions, as well as purified and non-purified conditions. Serial dilutions of BSA can be used as a standard to estimate the amount of purified GST- Raf1-RBD.

7. We assayed several concentrations of competing peptide, and an inhibitory effect was visible from $0.5 \mathrm{mM}$. At the same concentration, no effect of the control peptide is observed.

8. $\beta$-arrestins are "sticky" proteins. Hence, when investigating $\beta$-arrestin interaction partners in cell lysates, only a 5 min interaction time is enough, in order to avoid 
non-specific binding. However, with recombinant purified protein, this time had to be extended to one hour.

9. ERK peptides sequences :

\begin{tabular}{|l|l|}
\hline erk-antibarr-0 & ISPFEHQTY \\
\hline erk-antibarr-1.1 & RVAIKKISPFEHQTY \\
\hline erk-antibarr-1.2 & IKKISPFEHQTYCQR \\
\hline erk-antibarr-1.3 & ISPFEHQTYCQRTLR \\
\hline erk-antibarr-2.1 & IRDILRASTLEAMRD \\
\hline erk-antibarr-2.2 & ILRASTLEAMRDVYI \\
\hline erk-antibarr-2.3 & ASTLEAMRDVYIVQD \\
\hline
\end{tabular}

10. As initial concentrations of purified protein are often lower, calculate how much ng of protein you need for a triplicate. Then, prepare an intermediate solution at 1:10 with PBS(1X)-Tween $0.1 \%$, for each protein in a final volume of $50 \mu$ or 20 $\mu$ l. From 1:10 solutions, prepare mix of both proteins and adjust the final volume with PBS(1X)-Tween $0.1 \%$ to deposit $20 \mu \mathrm{l}$ or $10 \mu \mathrm{l}$ in one well of a 96-well plate or a 384-well plate, respectively.

11. To verify that HTRF-coupled antibodies recognize specifically tagged-proteins, prepare conditions with an irrelevant antibody. Also, to make sure that there is no cross-talk between secondary antibodies, prepare triplicate wells with only antibodies. Finally, to subtract medium background, prepare triplicate of PBS(1X)-Tween 20 only.

12. Preincubation allows the peptides to associate with the proteins. This association might be perturbed by the antibodies used for detection since the affinities of the peptides for the proteins are low (usually in the high micromolar range), whereas the affinities of antibodies binding to their targets are very high. Do not forget to prepare each condition with and without peptides. Since some complexes may gain in stability over time, it is recommended to keep the plate at $4^{\circ} \mathrm{C}$ and make repeated measures along 3-4 days (Figure 2C). 
13. After plate reading, results are present in an Excel table were two sequential readings at $620 \mathrm{~nm}$ and $665 \mathrm{~nm}$ emission wavelengths are performed. The ratio of the fluorescence intensities 665/620 $\mathrm{nm}$ (acceptor/donor) enables the calculation of Delta F, which represents the relative energy transfer rate for each sample. Finally, to subtract medium background, prepare triplicate of PBS(1X)Tween 20 only.

14. Start by setting the loading in an independent experiment. It is preferable that the loading curves remain linear (not reaching a plateau) as over-saturation of the biosensor is likely to induce the loading of a non-specific second layer of protein or peptide that will dissociate during the following baseline step. It is also possible to stop the loading before the plateau appears. Proper loading control consists in the absence of loading of the same protein in its non-biotinylated form and at the same concentration.

15. If possible, set the loadings of the relevant peptide and of the non-relevant peptide so they reach the same light deviation.

16. Make a preliminary run to determine the analyte concentration range. Typically, prepare 4 to 5 concentration points, in serial log dilutions (dividing concentration by ten at each dilution), starting at 10 times the expected $\mathrm{Kd}$. Select the range in which clear association curves are visible while not over-spending your sample.

17. Interferometry allows measuring the dissociation constant of a protein complex (Kd), even for the medium-high affinities of signalling modules. The present methodology describes the analysis of the association between a peptide and a protein. This type of complex has a very low affinity and since the measurement of the $\mathrm{Kd}$ requires 5 association curves of the protein over the peptide, the quantity of protein necessary may be high (up to milligrams). You may however observe the interaction between the peptide and the protein at one single concentration, even if it does not provide a $\mathrm{Kd}$. 
18. This methodology can also be used to measure the interaction between the two partner-proteins. In that case, peptide $\alpha$ should be replaced by the biotinylated partner of $\beta$-arrestin.

19. It is important to appreciate that it may be difficult to visualize the interaction between 2 partners when their molecular weight is more than 100-fold different. This drawback can be overcome when the smallest of the 2 proteins is loaded on the biosensor. This is why it is important here to load the peptide on the biosensor and not the protein. 


\section{Acknowledgements}

This publication was funded with support from the French National Research Agency under the program "Investissements d'avenir" Grant Agreement LabEx MabImprove: ANR-10-LABX-53 ; ANR (Contract $n^{\circ}$ ANR-2011-1619 01) ; ANR GPCRnet; MABSILICO, "ARD2020 Biomédicament" grants from Région Centre 32000593 APR BIOMEDICAMENT).

\section{References}

1. Crepieux P, Poupon A, Langonne-Gallay N, et al (2017) A comprehensive view of the $\beta$-arrestinome. Front Endocrinol 8

2. Kiel C, Verschueren E, Yang J-S, et al (2013) Integration of protein abundance and structure data reveals competition in the ErbB signaling network. Sci Signal 6:ra109

3. Kim PM, Lu LJ, Xia Y, et al (2006) Relating Three-Dimensional Structures to Protein Networks Provides Evolutionary Insights. Science 314:1938-1941

4. Kiel C, Vogt A, Campagna A, et al (2011) Structural and functional protein network analyses predict novel signaling functions for rhodopsin. Mol Syst Biol 7:551

5. Kar G, Gursoy A, and Keskin O (2009) Human Cancer Protein-Protein Interaction Network: A Structural Perspective. PLOS Comput Biol 5:e1000601

6. Wang X, Wei X, Thijssen B, et al (2012) Three-dimensional reconstruction of protein networks provides insight into human genetic disease. Nat Biotechnol 30:159164

7. Cunningham BC and Wells JA (1989) High-resolution epitope mapping of hGHreceptor interactions by alanine-scanning mutagenesis. Science 244:1081-1085

8. Forsström B, Axnäs BB, Stengele K-P, et al (2014) Proteome-wide Epitope Mapping of Antibodies Using Ultra-dense Peptide Arrays. Mol Cell Proteomics 13:15851597

9. Hansen CS, Østerbye T, Marcatili P, et al (2017) ArrayPitope: Automated Analysis of Amino Acid Substitutions for Peptide Microarray-Based Antibody Epitope Mapping. PLOS ONE 12:e0168453

10. Opuni KF, Al-Majdoub M, Yefremova Y, et al (2016) Mass spectrometric epitope mapping. Mass Spectrom Rev 9999:1-13

11. Wei H, Mo J, Tao L, et al (2014) Hydrogen/Deuterium Exchange Mass Spectrometry for Probing Higher Order Structure of Protein Therapeutics: Methodology and Applications. Drug Discov Today 19:95-102

12. Bourquard T, Landomiel F, Reiter E, et al (2015) Unraveling the molecular architecture of a $\mathrm{G}$ protein-coupled receptor/ $\beta$-arrestin/Erk module complex. Sci Rep 5:10760

13. Cassier E, Gallay N, Bourquard T, et al (2017) Phosphorylation of $\beta$-arrestin2 at Thr383 by MEK underlies $\beta$-arrestin-dependent activation of Erk1/2 by GPCRs. eLife 6:e23777

14. Bourquard T, Bernauer J, Azé J, et al (2009) Comparing Voronoi and Laguerre tessellations in the protein-protein docking context, Presented at the Voronoi Diagrams, 2009. ISVD'09. Sixth International Symposium on Voronoi Diagrams

15. Azé J, Bourquard T, Hamel S, et al (2011) Using Kendall- $\tau$ meta-bagging to improve protein-protein docking predictions, In: Pattern Recognition in Bioinformatics, pp. 284-295 Springer Berlin Heidelberg

16. Bourquard T, Bernauer J, Azé J, et al (2011) A collaborative filtering approach for 
protein-protein docking scoring functions. PLoS One 6:e18541

17. Berman HM, Westbrook J, Feng Z, et al (2000) The Protein Data Bank. Nucleic Acids Res 28:235-242 


\section{Figure legends}

Figure 1: A. Principle of the GST-pulldown experiment with purified proteins. B. Representative experiment to illustrate the disruption of the Raf1/ $\beta$-arrestin 1 interaction by a competing peptide (73-ISPFEHQTY-81). In each condition, 25 ng of $\beta$ arrestin 1 are added, whereas GST-Raf1-RBD is not present in the last lane. The same membrane hybridized with an anti-GST antibody to monitor the pulled-down amount of GST-Raf-RBD is shown below. C. Quantification of three independent experiments.

Figure 2: A. Principle of the HTRF experiment. B. Quantification of three independent experiments showing $\beta$-arrestin 1 interaction with competing peptides after $3 \mathrm{hrs}$ of incubation. Sequences of the peptides are given in Note 9. The control peptide is a portion of the sequence of the C5 complement protein. Different letters above the bars indicate statistically significant differences. C. Quantification of three independent experiments showing $\beta$-arrestin 1 interaction with selected competing peptides after either $1 \mathrm{hr}, 3 \mathrm{hrs}$ or 3 days of incubation.

Figure 3: A. Principle of the interferometry experiment: biotinylated specific peptide or control peptide binds to the streptavidin tip. $\beta$-arrestin then binds to the interfering peptide but not to the control peptide. B. Sample plate scheme. Samples and buffer are loaded on the black 96-well plate as shown here. The peptides $\alpha$ and $\gamma$ are prepared at one single concentration whereas protein $\beta$ is prepared in five concentrations. Well A4 contains only kinetic buffer and will be used as control. C. Representative experiments to illustrate the observation by biolayer interferometry of the specific interaction between the competing peptide ERK2-3 and $\beta$-arrestin 1.

Figure 4: Principles for refining the design of peptides. See text for details. 

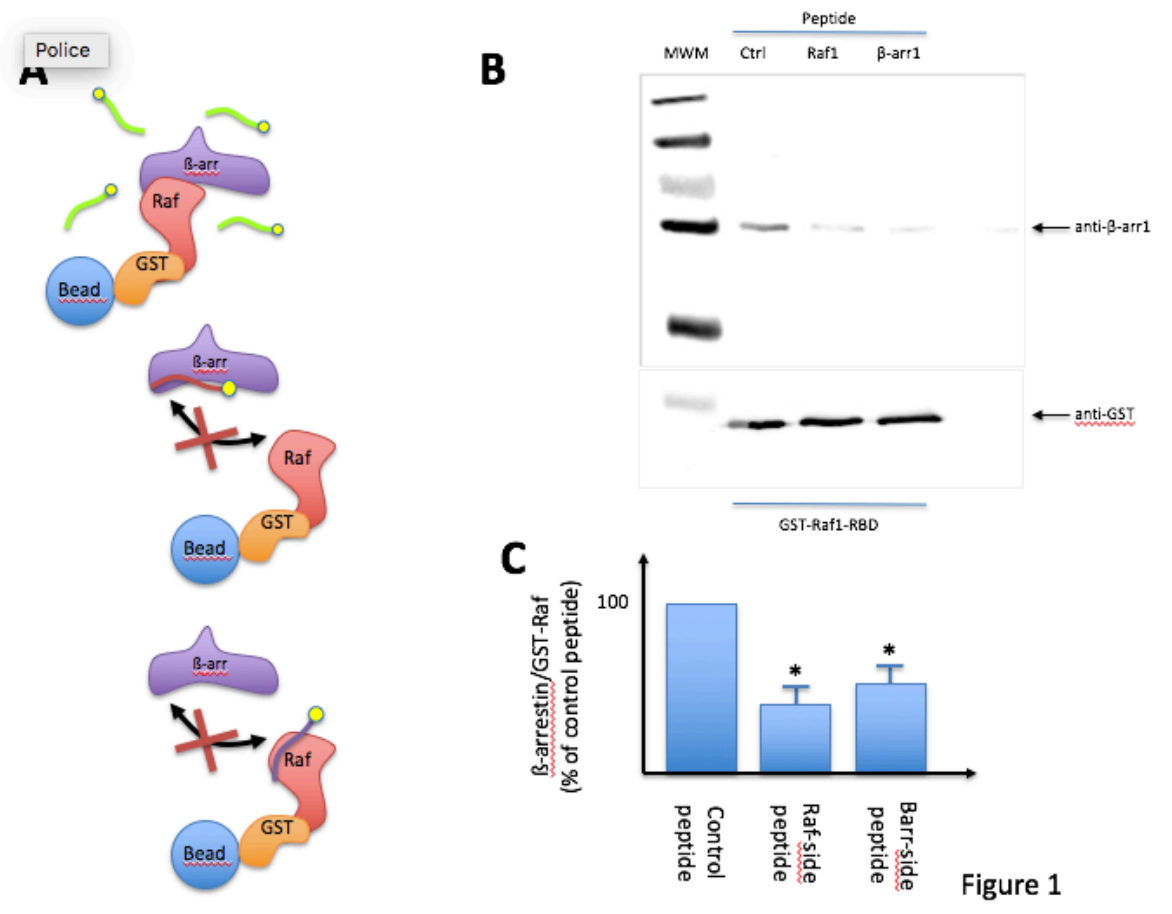

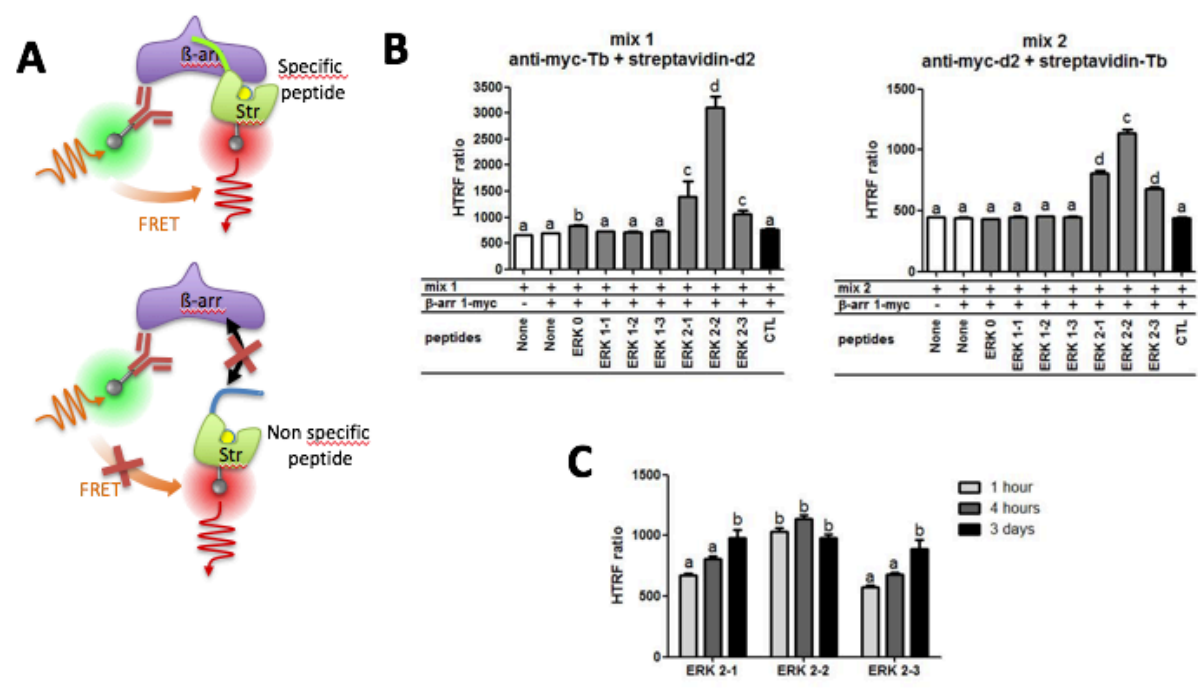

Figure 2 
A

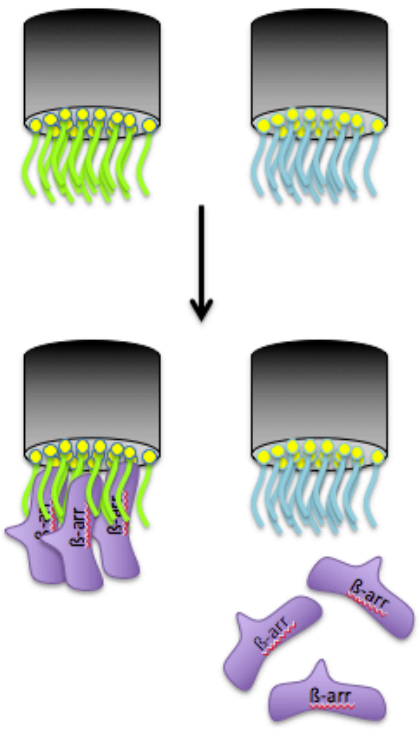

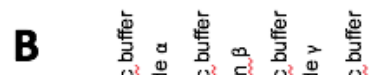

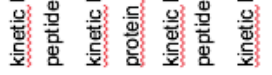
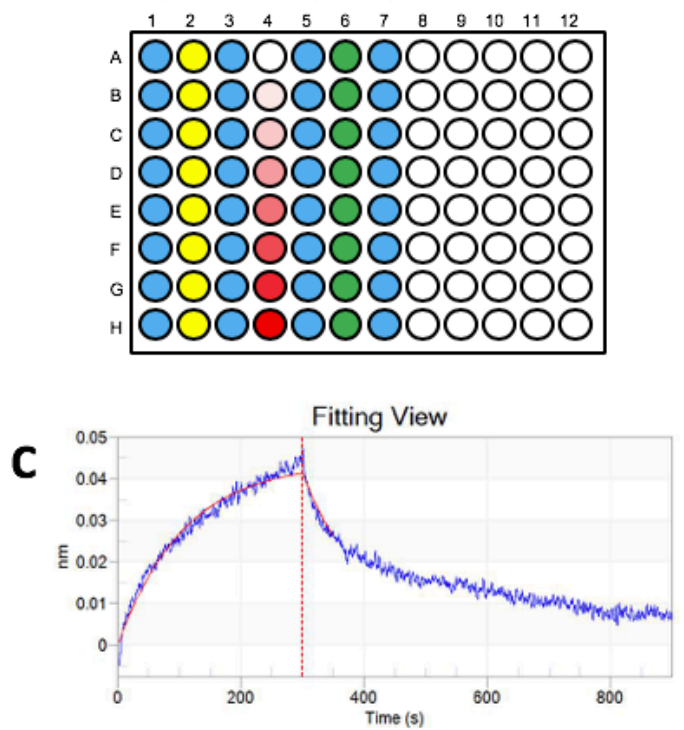

Figure 3 

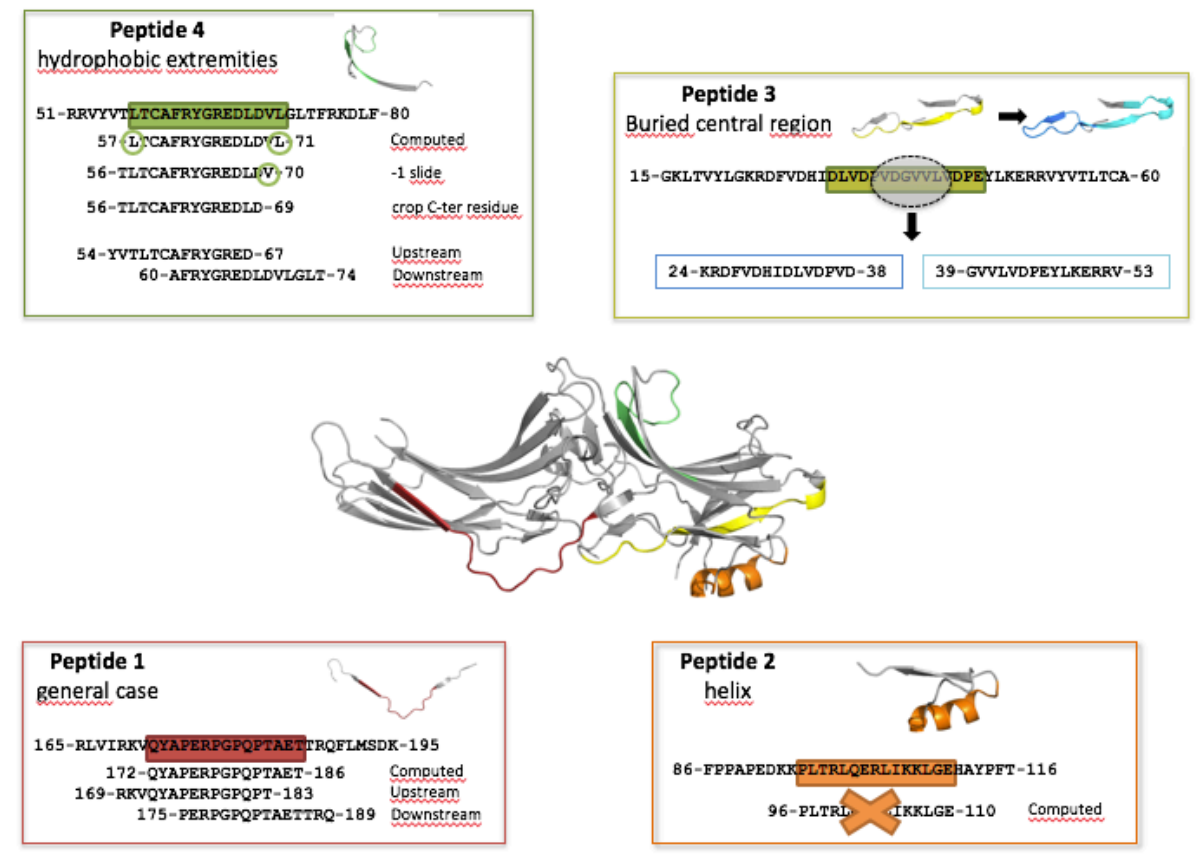

Figure 4 